\title{
RESOURCES MANAGEMENT AND SME'S PERFORMANCE
}

\section{Aurangzeb $^{1 *}$, Muhammad Asif ${ }^{2}$, Muhammad Kashif Amin ${ }^{3}$}

${ }^{1 *}$ Professor, Dean of Management Sciences, Preston University, Kohat, Pakistan; ${ }^{2}$ Visiting Faculty, Preston University, Islamabad, Pakistan; ${ }^{3}$ Research Scholar, Federal Urdu University of Arts, Science and Technology, Islamabad, Pakistan.

Email: "mahboobmails@gmail.com

Article History: Received on $27^{\text {th }}$ May 2021, Revised on $2^{\text {nd }}$ June 2021, Published on $3^{\text {rd }}$ June 2021

\section{Abstract}

Purpose of the Study: This study aimed at investigating the level of tangible and intangible resources management of small and medium-sized enterprises (SMEs) entrepreneurs that affect the business unit performance.

Methodology: The population used in this study was 300 entrepreneurs and executives representing businesses in Pakistan's production and service sectors. This study was quantitative, and data was collected through questionnaires related to business performance. There were three factors of intangible resource management, i.e., human capital management, relationship capital management, and customer capital management. Data were analyzed using structural equation modelling.

Principal Findings: The outcomes indicated that human capital management and customer capital management positive and significant influence on the business performance of SMEs, whereas no influence on capital management. Technology capital management fully mediates the association between human capital management and customer capital management.

Applications of the study: This study is useful in strategic management and implementation to build relation capital among approximately 6 million business units of SMEs and micro SMEs in Pakistan, which will lead to the strong foundations of the country.

Novelty/Originality of this study: The present study examined the resources management practices of SMS across the country for the first time that indicates that how efficient resource management practices influence the performance of business units and entrepreneurs in a developing economy like Pakistan.

Keywords: Small and Medium-sized Enterprise, Human Capital, Relationship Capital, Customer Capital, Organization Capital, Technology Capital, Business Performance.

\section{INTRODUCTION}

Successful business operation is measured by business performance (BUP) and economic expansion. Still, the previous political crisis and economic slowdown in the country have affected the economic contraction and the consumption of the people, causing "SMEs" to have problems doing their businesses. However, the economy is going in a positive direction that can be seen from the value of domestic economic expansion, as shown in Table 1 below.

Table 1: Values of the gross domestic product during 2014-2018 classified by enterprise size

\begin{tabular}{ccccccc}
\hline Year & $\mathbf{2 0 1 4}$ & $\mathbf{2 0 1 5}$ & $\mathbf{2 0 1 6}$ & $\mathbf{2 0 1 7}$ & $\mathbf{2 0 1 8}$ & $\mathbf{\%}$ \\
\hline Country & $13,230,301$ & $13,743,463$ & $14,554,571$ & $15,451,955$ & $16,318,033$ & 100.00 \\
\hline Agriculture & $1,334,795$ & $1,219,421$ & $1,229,565$ & $1,286,171$ & $1,324,140$ & 8.11 \\
\hline Non agriculture Large & $5,831,626$ & $6,049,200$ & $6,343,238$ & $6,690,504$ & $7,026,109$ & 43.06 \\
\hline Enterprise SME & & & & & & \\
\hline - Small & $3,702,077$ & $3,975,944$ & $4,321,071$ & $4,666,961$ & $5,010,991$ & 30.71 \\
\hline $\begin{array}{c}\text { Enterprise } \\
\text { - Medium }\end{array}$ & $1,559,013$ & $1,655,482$ & $1,778,114$ & $1,890,789$ & $2,002,980$ & 12.27 \\
\hline $\begin{array}{c}\text { Enterprise } \\
\text { Other }\end{array}$ & 1802,790 & 843,416 & 882,583 & 917,530 & 953,813 & 5.85 \\
\hline
\end{tabular}

Source: Office of the National Economic and Social Development Board

From Table 1 indicating the values of the country's gross domestic product (GPD) classified by economic activity and enterprise size, SMEs have been still important continuously. The values of the GDP of SMEs have increased until they are close to those of large enterprises. This represents an ever-increasing role in the economy of SMEs. Besides the importance of building the overall economy in the country, the importance of SMEs has also played a role in worker employments, as shown in Table 2 below.

Table 2: Number of establishments and worker employments during 2017-2018 classified by business group

\begin{tabular}{|c|c|c|c|c|c|c|c|c|}
\hline \multirow{3}{*}{$\begin{array}{c}\begin{array}{c}\text { Business } \\
\text { group }\end{array} \\
\end{array}$} & 2017 & \multicolumn{2}{|c|}{2018} & \multicolumn{2}{|c|}{2017} & \multicolumn{3}{|c|}{2018} \\
\hline & Number of & Number of & Number of & Number of & $\%$ of & $\%$ of & $\%$ of & $\%$ of \\
\hline & establishments & employments & Establishments & employments & establishments & employments & establishments & employments \\
\hline
\end{tabular}




\begin{tabular}{lcccccccc}
\hline & (enterprise) & (person) & (enterprise) & (person) & & & \\
\hline Trading & $1,268,201$ & $4,239,434$ & $1,279,557$ & $4,438,558$ & 42.26 & 32.54 & 42.21 \\
\hline Service & $1,206,762$ & $5,666,017$ & $1,224,563$ & $6,052,338$ & 40.21 & 43.5 & 40.39 \\
\hline Production & 525,974 & $3,121,439$ & 527,485 & $3,394,301$ & 17.53 & 23.96 & 17.4 \\
\hline Total & $3,000,937$ & $13,026,890$ & $3,031,605$ & $13,885,197$ & 100 & 100 & 100 & 100 \\
\hline
\end{tabular}

Source: Office of Small and Medium Enterprises Promotion

Table 2 indicates three 3 million SMEs established in the trading, service, and production sectors, including the number of employments as a driving force of the economy according to the SMEs promotion plan.

According to the roles and importance of SMEs as mentioned above, the problem faced by SMEs in almost every age is access to funding sources due to limitations of collaterals, government laws, and poor internal management, such as entrepreneurial knowledge and skills, including poor marketing management, such as distribution channels and use of technologies

to help in supporting the sale of their products and services. From the problems mentioned above, it was found that 391 SMEs were liquidated in 2018 that was higher than the number in 2017. The reasons for the termination of their operations were due to the slowdown in the economy of the country and the world, fierce trade competition, and higher labor costs, causing the operating costs to be higher as well, although SMEs in the production and service sectors had the higher gross product values, the number of establishments, and the number of worker employments.

From the problems mentioned above, the business operations of SMEs must adapt themselves to keep up with the rapidly changing knowledge and environment in the creation of their products and services to keep up with the rapidly changing needs of consumers (Olufunmilola \& Helen, 2016). Therefore, SME entrepreneurs will be successful and able to stand up to the current conditions with big economic changes are required to have a method for rapid resource management adaptation in terms of both internal and external resources factors. In the digital economy age, entrepreneurs need to understand and value intellectual capital management for organizational success as measured by business unit performance. The main drivers of SMEs are intellectual capital management, known as corporate resources, or soft management, i.e., human capital, customer capital, relation capital, and hard management, i.e., organization capital and technology capital.

\section{Research Objectives}

- To investigate the level of tangible and intangible resource managements of SME entrepreneurs; and

- To investigate the causal model in the context of intangible resource management and tangible resource management that affects the business unit performance (BUP) of small and medium-sized enterprises (SMEs).

\section{LITERATURE REVIEW}

\section{Human Capital Management (HCM)}

Human capital refers to knowledge and skills in the works of employees obtaining from their learning through actual operations and training courses, leading to their expertise, also known

as skills and experiences or expertise attached to themselves. These knowledge and skills are then used to improve their work efficiency by reducing unnecessary operating processes to save time and other resources.

According to Khan and Ullah (2021), investigating the ability of individual entrepreneurship and performance of SMEs, the importance of human capital and organization capital in determining the performance of SMEs were analyzed by proposing and testing the designated individual entrepreneur models of two types of capital: human capital and organization capital. An empirical test was done with a sample of 300 SMEs in Pakistan. Human capital was considered in three dimensions: 1) personal characteristics (enthusiasm for work), 2) pushing management, and 3) pulling management. Organization capital was considered in four dimensions: 1) behavior of individual entrepreneurs, 2) behavior of overall entrepreneurs, 3) management practice, and 4) organizational culture (in terms of special and social structures). For findings on human capital, personal characteristics could drive effective and efficient management that may be passed on to organization capital to strengthen the organizational culture and organizational structure to support efficient SME operations.

\section{Relation Capital Management (RCM)}

Relation capital refers to knowledge arising from interactions between individuals or businesses with joint activities (Ullah, Afghan, \& Afridi, 2019) general, those with higher potential tend to provide knowledge to their partners so that the recipients can make use of it. Examples of relation capital are supporting and educating about raw materials that customers will use to create good products and helping to find new customers and marketing channels. Relation capital is fundamental to social, and business supports between business partners. The knowledge gained through relation capital will lead to cost reduction and increased quality and productivity of products and services. In addition, relation capital also contributes to innovations. Thus, relation capital can help increase intellectual capital, which is an important 
resource and can be done at all levels. At the operational level, strategies can motivate employees to use the knowledge gained from relation capital to develop and add product values (Lawson et al., 2008).

According to Olufunmilola and Helen (2016), regarding the relationship between organizational adaptation and learning, the direct relationship between entrepreneurial adaptation and organizational learning and the use of technologies in SMEs influenced entrepreneurship and mutual business relationship. This demonstrates that strategic partnership and organizational performance play a mediating role in relationships that drive the business unit performance of SMEs.

\section{Customer Capital Management (CCM)}

Customer capital refers to the loyalty of the customers and the relationship of the businesses with the customers, leading to value creation in selling products and providing services to customers. Customers are classified by customer involvement that leads to the intangible assets of the organizations. Customer capital is an integral part of intellectual capital, which is created

by good interactions between the customers and the businesses. It can be compared that the value of a customerorganization relationship is a type of asset. Therefore, developing and maintaining loyalty to the customers of the organizations is considered an important factor in creating a competitive advantage in the knowledge-based economy. It also plays a key role in driving strategies for promoting financial performance in marketing dimensions (Ullah, Afghan, \& Afridi, 2019).

According to Al-Maamari and Abdulrab (2017), customer satisfaction and loyalty through the introduction of products and services, the knowledge gained from introducing products and providing services can result in customer satisfaction while the businesses can gain financial value. In addition, receiving customer feedback is a factor that affects the loyalty of customers towards the organizations. There are six important factors: service quality, pleasant perception, technological perception, perceived value, trust, and customer satisfaction, which affect customer reliability. Moreover, the factors of technological perception include basic factors in technologies and safety in the use of technologies for customer relationship management as well as in the development of organization's operations from the use of information technology and networking system to expand customer relationship management with large suppliers and customers (Ullah, Malik, Zeb, \& Rehman, 2019).

\section{Organization Capital Management (OCM)}

Organization capital is the infrastructure capital that supports the success of the organizations (Azadeh, 2017). It also includes corporate culture, policies, and working processes under technologies. Overall, the organization capital is the result of an integration of technologies and knowledge from business processes that have been established as a principle and guideline of works and incentives for perception. According to Edvinsson \& Malone (1997), organization capital consists of operational steps, production techniques, corporate communications, and other supporting policies and mechanisms. In addition, according to Subramaniam \& Youndt (2005), the foundation of organization capital is derived from acquiring knowledge and experiences and developed as organizational structure and work processes. According to Azadeh (2017), the organization's capital cannot be reported in the financial statements due to its complexity of occurrence.

According to Fiala \& Borůvková (2012), the organization capital value was validated to create a model for measuring organization capital using a sample of 2,796 companies in the Czech Republic and using the regression equation in the analysis. It was found that the organization's capital had a significant effect on the ratio of return on equity (ROE) and return on assets (ROA). According to Ullah (2020), the organizational competence impact on business unit performance was investigated using information from medium to large Turkish manufacturers and exporters. The study found that increasing the level of organizational competence had a positive effect on business unit performance.

\section{Technology Capital Management (TCM)}

In the age of a knowledge-based economy, the role of technology capital is highly recognized. According to Fernandez. et al. (2000), technology capital includes acquiring and applying knowledge to develop product innovations, services, or production processes to compete. As for the management that requires knowledge to adjust the organizational structure or create a new management approach, there is an investment in the development of management innovations in different functions, such as management techniques, financial methods, and unique marketing methods or management innovations. IT resources are ICT infrastructure in human resources and assets of knowledge in software and rights in connection with technologies (Gunasekaran et al., 2006), capital, and resources, such as shared efficiency and expected development potential of the businesses. Therefore, only one aspect of technology capital is not as effective as it should be, but it requires strategic technology management and effective inspection to control resource management related to business operations.

According to Lin (2007), information technology affecting the organizational structure and business unit performance found that information technology had direct and indirect effects on business unit performance. According to Gunasekaran et al. (2006), regarding the adaptation of technologies, IT planning affected the creation of innovations while innovations affect the efficiency of the businesses. 


\section{Business Performance (BUP)}

Business Performance is a success in the form of benefits that a company receives from its operations. It depends on internal (human capital, organization capital, relation capital, and technology capital) and external factors (customer capital and stakeholders). Appropriate management of internal and external factors is an important ground. An important internal factor of the organization is human capital, which is inserted into the works of the organization's activities at both management and operational levels, leading to the success factor of the organization, i.e., human capital management (Murphy, 2002). Therefore, the traditional style of human resource management has become a human resource management strategy that executives at all levels pay attention to. However, the determination and implementation of strategies in practice in all sectors of the organizations are difficult and complicated due to many conditions, such as differences in various areas and relationships between different subunits.

Different requirements determine today's business environment. A measurement and evaluation of business unit performance use indicators and criteria that have been continuously developed while there are many possibilities for evaluating a business unit's performance. The first and easiest way is to evaluate performance with one selected indicator depending on the company's goals. For example, if the goal is to maximize profit, the criterion for evaluating business unit performance is profit achieved. This method is suitable for small businesses with simple business conditions.

\section{Related Theories}

\section{Human capital theory}

Human capital is an intangible asset that a person has. It is the knowledge and skills that a person uses to level up his/her value, employers, and society. Overall, human capital theory considers labor as a commodity that can be bought and sold. This theory puts a lot of emphasis on labor. Education and training allow employees to gain skills, expertise, and knowledge in their actual work, which is more valuable. According to Ullah (2020), in the progression of business unit performance, the organizations have focused on developing operational training, which is linked to collective traits with people.

According to Becker et al. (1996), the main factors of production are land, labor, physical capital, and human resource management. This is a theoretical and empirical analysis regarding education, indicating that there are different types of capitals, including education and curriculum training, that is, learning skills. It is an investment in human capital and is an investment that offers valuable and calculable returns.

\section{Knowledge-based theory of the firm (KBT)}

According to Clarke \& Rollo (2001), the knowledge contained within the companies is the key that provides them with a competitive advantage and leads to good business unit performance as desired by organizations.

According to Nonaka, Toyama \& Konno (2000), the knowledge accumulated within employees makes each employee in the organization different from other employees due to their different accumulated knowledge combined with personal attitudes and experiences and their different operating procedures and methods. Therefore, the knowledge and abilities of the employees within the organizations or members within the groups cannot be substituted because each employee has different knowledge, skills, and expertise in each area. These different values arise from sharing, which is very important. The knowledge sharing and transfer can also fill the knowledge between employees, add value to human resources in the organization and increase intellectual capital and human capital at the same time.

\section{Dynamic capabilities theory}

This theory was first introduced by Teece and Pisano in (1994) and explained how to create a competitive advantage. According to Teece et al. (1997), successful businesses in the global marketplaces can show a timely response to market fluctuations. Organizations that can efficiently deploy internal and external capabilities will have a high competitive advantage. The consideration of dynamic capabilities focuses on three fundamental factors: coordination, learning, and reconfiguration.

According to Adner and Helfat (2003), the concept of dynamic management capabilities was presented to explain the differences in management and corporate strategy decisions. There are three basic management capabilities: 1) human capital management, 2) social capital for management, and 3) management knowledge. The reason for discrepancies in decisions is management decisions depending on the organization's capabilities and resources. The differences between organizational resources and competencies can lead to differences in management decisions and differentiate organizational performance. According to Wang and Ahmed (2007), three elements that reflect the common properties of dynamic capabilities in organizations were proposed: 1,) Adaptability refers to the ability to Take advantage of market opportunities; 2) Absorbability refers to the ability to use external data for commercial purposes. Organizations with a higher absorbability are better able to learn from their partners and turn learned knowledge into competencies, and 3) Innovative capability refers to developing a new product or market. These elements describe how resources and capabilities are used to maintain organizational performance over the long term. 
From the studies of (Khan and Ullah, 2021; Wang and Ahmed, 2007), the author developed the below conceptual framework from theories and studies related to soft management (human capital, relation capital, and customer capital) and hard management (organization capital and technology capital) that affect business unit performance. The author summarized and created the conceptual research framework as follows:

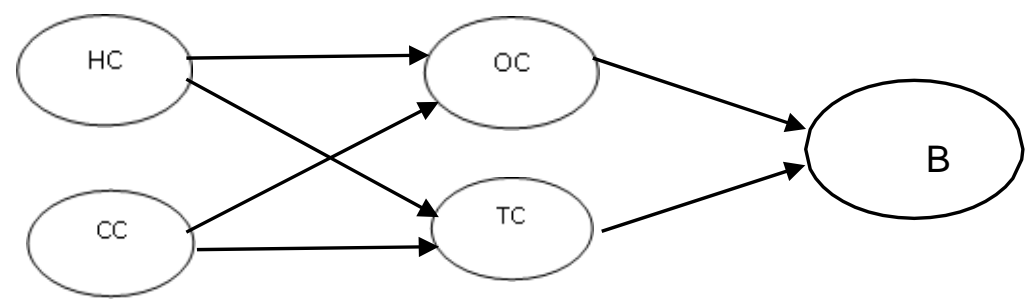

Figure 1: Conceptual Framework

\section{Research Hypotheses}

$\mathbf{H}_{1}$ : Intangible resource management positively and significantly influences tangible resource Management.

$\mathbf{H}_{2}$ : Tangible resource management positively business unit performance.

$\mathbf{H}_{3}$ : Technology capital management mediates between human capital management, and customer capital management.

\section{RESEARCH METHODOLOGY}

For the accomplishment of the research objective, the data were collected from relevant documents by researching theories, concepts, research results, and academic works obtained from documents, books, articles, or information from other sources that were defined or studied in the past, to understand the theories and principles of intangible and tangible resource management as a foundation for the basic knowledge of questionnaires for data collection. Hence, data were collected through questionnaires from 300 entrepreneurs and executives out of 450, representing the businesses in the manufacturing and service industries located in Pakistan using closed-end questions.

For quantitative research, the current study conducted a data analysis approach based on conditions and suitability of data and research objectives. Descriptive statistics were used in an analysis of questionnaires of variables by finding the frequency of variables and summarizing them as a percentage, while a rating scale was used to measure the difference of variables by finding the mean and standard deviation to obtain the minimum and maximum values; and Inferential statistics were used to test hypotheses through an analysis of causal relationships by confirming the relationships of each variable and finding the levels of factors with direct, indirect, and total influences of each variable using structural equation modelling (SEM).

\section{RESULTS}

Descriptive statistics were used to analyze and compare the total mean of each factor in the conceptual framework of SMEs in the manufacturing and service sectors, as shown in Table 3 below.

Table 3: Comparison of total mean of each factor in the conceptual framework

\begin{tabular}{lclll}
\hline Factor & Mean & Standard deviation & Coefficient of & Level \\
\hline & $(\mathrm{X})$ & $(\mathrm{SD})$ & variation $(\mathrm{CV})$ & \\
\hline Human capital & 3.922 & 0.753 & 0.192 & High \\
\hline Relation capital & 3.662 & 0.870 & 0.238 & High \\
\hline Customer capital & 4.026 & 0.776 & 0.193 & High \\
\hline Organization capital & 3.989 & 0.755 & 0.189 & High \\
\hline Technology capital & 3.725 & 0.856 & 0.230 & High \\
\hline Business performance & 3.797 & 0.811 & 0.214 & High \\
\hline
\end{tabular}

From Table 3, as for intangible resource management, the customer capital had the highest mean at 4.026, and the coefficient of variation was $19.3 \%$, while the mediator factor was tangible resource management. The organization capital had the highest mean at 3.989 , and the

coefficient of variation was low at $18.9 \%$. The business performance, as an output factor, had a low mean at 3.797 , and the coefficient of variation was high at $21.4 \%$. This indicates that intangible resource management must consider "relation capital" in the business operations and human capital and customer capital. However, when considering the mediator factor to the tangible resource management, it must consider using "technology capital" in the organizations' business operations to strengthen business performance and achieve even more stability.

Inferential statistics were used to test hypotheses from the model of a sample of SME entrepreneurs under the factors of human capital management, relation capital management, customer capital management, organization capital management, technology capital management, and business performance. An analysis of structural equations specified 
constraints to adapt to the fit model by performing the same actions on each group. The analysis is divided into steps. The results are shown in Figure 2 below.

(1) Inspection CFA (Confirmatory Factor Analysis) to see the suitability of dividing variables in each factor (latent variable). The results appear as follows.

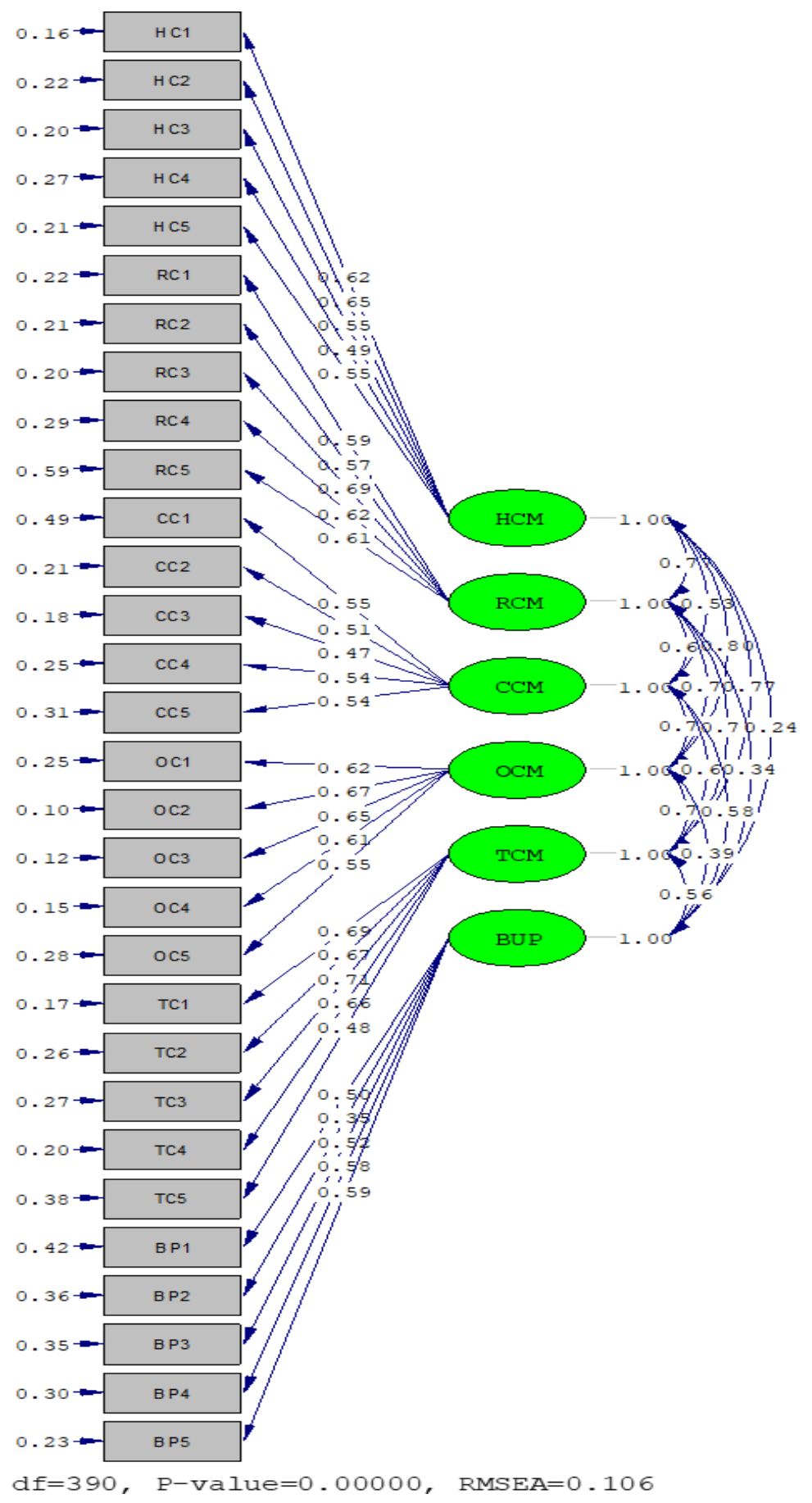

Figure 2: CFA Analysis

\section{Test result}

Chi-Square / df $=3.766$.

Normed Fit Index $(\mathrm{NFI})=0.934$.

Parsimony Normed Fit Index $($ PNFI $)=0.939$.

Comparative Fit Index $(\mathrm{CFI})=0.951$. 
Root Mean Square Residual $(\mathrm{RMR})=0.045$.

Root Mean Square Error Average (RMSEA) $=0.106$

Goodness of Fit Index (GFI) $=0.845$.

It is considered that the suitability of the model in factor classification is good.

(2) Inspection EFA (Exploratory Factor Analysis) to determine the suitability of each latent variable, the results are as follows:

Table 4: Loading, AVE, and Composite Reliability values from EFA

\begin{tabular}{|c|c|c|c|}
\hline Factor & Loading & AVE & Composite Reliability \\
\hline HCM & & 0.679 & 0.914 \\
\hline $\mathrm{HC} 1$ & 0.870 & & \\
\hline $\mathrm{HC} 2$ & 0.852 & & \\
\hline $\mathrm{HC} 3$ & 0.818 & & \\
\hline $\mathrm{HC} 4$ & 0.757 & & \\
\hline HC5 & 0.820 & & \\
\hline $\mathbf{R C M}$ & & 0.655 & 0.904 \\
\hline $\mathrm{RC} 1$ & 0.830 & & \\
\hline $\mathrm{RC} 2$ & 0.824 & & \\
\hline RC3 & 0.870 & & \\
\hline $\mathrm{RC} 4$ & 0.812 & & \\
\hline RC5 & 0.702 & & \\
\hline CCM & & 0.601 & 0.883 \\
\hline $\mathrm{CC} 1$ & 0.726 & & \\
\hline $\mathrm{CC} 2$ & 0.832 & & \\
\hline $\mathrm{CC} 3$ & 0.823 & & \\
\hline $\mathrm{CC} 4$ & 0.749 & & \\
\hline $\mathrm{CC} 5$ & 0.741 & & \\
\hline OCM & & 0.739 & 0.934 \\
\hline $\mathrm{OC} 1$ & 0.817 & & \\
\hline OC2 & 0.912 & & \\
\hline OC3 & 0.906 & & \\
\hline OC4 & 0.879 & & \\
\hline OC5 & 0.775 & & \\
\hline TCM & & 0.695 & 0.919 \\
\hline TC1 & 0.846 & & \\
\hline TC2 & 0.866 & & \\
\hline TC3 & 0.870 & & \\
\hline TC4 & 0.847 & & \\
\hline TC5 & 0.731 & & \\
\hline BUP & & 0.544 & 0.855 \\
\hline BUP1 & 0.703 & & \\
\hline BUP2 & 0.649 & & \\
\hline BUP3 & 0.741 & & \\
\hline BUP4 & 0.737 & & \\
\hline BUP5 & 0.844 & & \\
\hline
\end{tabular}

From Table 4, EFA results support variable division among factors; Factor Loading ranges from 0.649 - 0.912 ; this is based on results from Hair et al. (1998) and MacCallum et al. (2001). However, when looking for AVE and Composite Reliability, it was found that AVE was higher than 0.5 and Composite Reliability was higher than 0.7. all factors.

(3) The results of analysis and adjustment for suitability using Covariance Based method. 


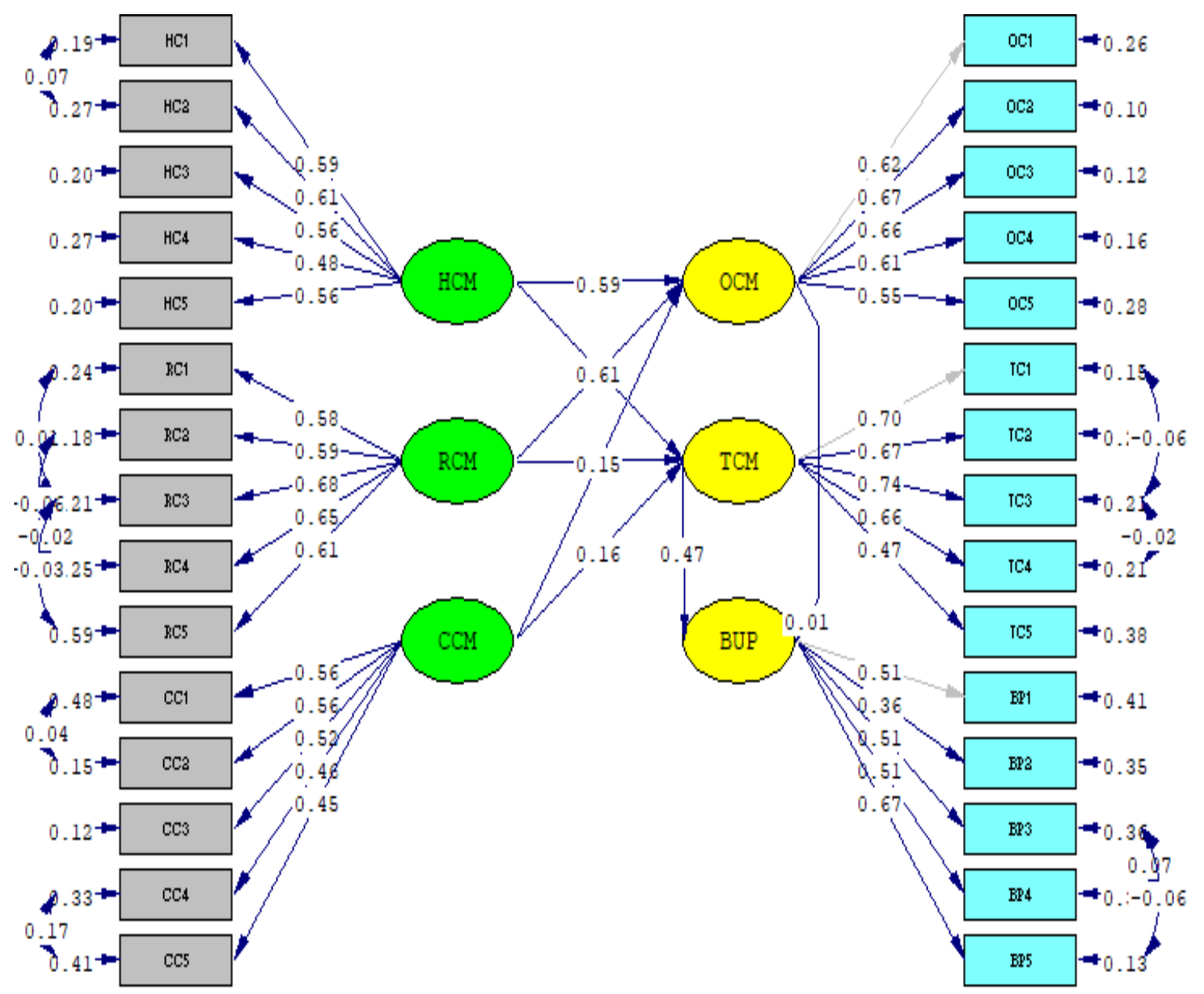

Chi-Square $=1135.62, \mathrm{df}=383, \mathrm{P}-\mathrm{value}=0.00000, \mathrm{RMSEA}=0.076$

Figure 3: The effect of adjusting the model

Table 5: Index harmonization standards value from the analysis of the conceptual model

\begin{tabular}{lllll}
\hline Index & Value & \multicolumn{2}{c}{ Standard } & \\
\hline Chi-Square & 1135.62 & - & & - \\
\hline Degree of & 383 & - & & - \\
\hline $\begin{array}{l}\text { Freedom } \\
\chi^{2} / d f\end{array}$ & 2.96 & $<=3.00$ & Good fit & Wheaton et al. (1997) \\
\hline RMSEA & 0.076 & $<0.08$ & Mediocre fit & MacCallum et al., (1996) \\
\hline P value & 0.000 & $>0.05$ & & \\
\hline NFI & 0.937 & $>0.90$ & Good fit & Bollen (1990); \\
\hline & & $>0.95$ & & Hu and Bentler (1999) \\
\hline
\end{tabular}

\begin{tabular}{|c|c|c|c|c|}
\hline CFI & 0.953 & $>0.90$ & Good fit & Hu and Bentler (1999) \\
\hline GFI & 0.845 & $>0.90$ & Acceptable & Sharma et al., (2005) \\
\hline AGFI & 0.814 & $>0.90$ & Acceptable & Sharma et al., (2005) \\
\hline IFI & 0.953 & $>0.90$ & Good fit & Miles and Shevlin (2007) \\
\hline RFI & 0.928 & $>0.91$ & Good fit & $\begin{array}{l}\text { Gerbing and Anderson (1993), Hu and Bentler (1999), Marsh et } \\
\text { al., (2004) Byme (1998); }\end{array}$ \\
\hline RMR & 0.048 & $<0.05$ & $\begin{array}{l}\text { Mediocre } \\
\text { fit }\end{array}$ & Diamantopoulos and Siguaw(2000) \\
\hline
\end{tabular}

Note: the results of running with Lisrel.

The test results in the model using ten harmonization standards values showed that the results were very good, five values (Good fit), Mediocre fit had two values, and the results were accepted (Acceptable) had two values. The disqualification has one $\mathrm{p}$-value. This is because $\mathrm{p}$-value $>0.05$ is used to verify suitability. It is often not used because 
such values are often unstable depending On the complexity of the subject (Number of empirical variables and Construct variables) and sample sizes used for analysis. In general, p-value> 0.05 results in not often used in judgment (Schlermelleh-Engel et al. 2003; Ullah,2020; Vandenberg, 2006). Therefore, the results of the conceptualized model analysis. Considered suitability is good.

Table 6: Results of hypothesis testing according to the research conceptual framework

\begin{tabular}{llll}
\hline Hypothesis & Coefficient & t-test & Result \\
\hline HCM $->$ OCM & $0.589^{* * *}$ & 7.599 & Supported \\
\hline HCM $->$ TCM & $0.606^{* * *}$ & 7.147 & Supported \\
\hline RCM $>$ OCM & 0.102 & 1.438 & Not supported \\
\hline RCM $->$ TCM & 0.146 & 1.866 & Not supported \\
\hline CCM $>$ OCM & $0.314^{* * *}$ & 6.099 & Supported \\
\hline CCM $>$ TCM & $0.157^{* *}$ & 2.920 & Supported \\
\hline OCM $->$ BUP & 0.008 & 0.097 & Not supported \\
\hline TCM $>$ BUP & $0.472^{* * *}$ & 4.833 & Supported \\
\hline RCM $>$ BUP & 0.070 & 1.819 & Not supported \\
\hline CCM $>$ BUP & $0.077^{*}$ & 2.373 & Supported \\
\hline
\end{tabular}

Note: The coefficients shown are standard coefficients and the criteria are $* \mathrm{p}=.05, * * \mathrm{p}=0.01$, and $* * * \mathrm{p}=0.001$.

From Table 6, there were three factors of intangible resource management, i.e., human capital management (HCM), relationship capital management (RCM), and customer capital management (CCM). It was found that human capital management (HCM) had the highest total influence on business unit performance (BUP) of SMEs, 0.291, followed by customer capital management (CCM), 0.077. In contrast, it did not influence relationship capital management (RCM). The mediator factor was technology capital management serving as a mediator variable between the human capital management (HCM) and the customer capital management (CCM) leading to business unit performance (BUP) with an influence of 0.472 , equivalent to 5 times.

This study aimed at investigating the level of tangible and intangible resources management of small and medium-sized enterprises (SMEs) entrepreneurs that affect the business unit performance. According to the model used in this study, it can be said that businesses should manage their intangible capitals, including human capital and customer capital. Human capital is a factor that creates customer capital in terms of perception of customer needs to design products/services to meet their needs. Even in the case of service businesses, building customer relationships is an extremely important factor in the competitions. Therefore, in managing SMEs, despite the small number of personnel, an improvement of employee performance by investing in training to increase their skills, knowledge, and competency can help drive the creation of tangible corporate assets, including economic value from profit and value from increased knowledge base as proved by (Azadeh, 2017; Fiala \& Boruvkova, 2012; Olufunmilola and Helen, 2016; Khan and Ullah, 2021). As for the problem of relation capital that did not appear to be significant in driving the organization's business unit performance, they should be grouped as a cluster to create the power to share knowledge and reduce the cost of human resource development. In addition, networking can help reduce the cost of purchasing products from the manufacturers and build the ability to compete with large companies. Moreover, human capital management should be done before investing in the development of technologies because if human capital is not competent enough, investing in technologies can sometimes be wasted. The outcomes of this study are consistent with (Al-Maamari and Abdulrab, 2017; Ullah, Afghan, \& Afridi, 2019) that have provided evidence that human capital management and customer capital management had the strongest real influence on the business performance of SMEs, whereas no influence on capital management.

\section{CONCLUSION}

The results documented that human capital management and customer capital management had a significant positive impact on the business performance of SMEs, whereas no influence on capital management. Furthermore, the outcomes show that technology capital management fully mediates between the human capital management, and the customer capital management.

Therefore, companies that invest in human capital have a competitive advantage and are an important source of increasing returns and differentiation in economic growth rates.

\section{LIMITATION AND STUDY FORWARD}

Due to the limitations in "relation capital management in SMEs," the relation capital management in a dimension of potential entrepreneurs can help support inferior entrepreneurs in different matters, such as by providing knowledge about raw materials that customers will use to develop and create good products and services and helping to find customers or marketing channels for businesses that have a mutual relationship, which is social support. Furthermore, the knowledge gained through relation capital will improve products and services cost, quality, and productivity, including innovations. Therefore, further research may be done at both the management and operational levels. As for 
the operational level, the research can examine strategies to motivate employees to use the knowledge obtained from relation capital to develop product value-added. In addition, the research may select successful businesses under the networks and alliances to find their models.

\section{AUTHORS' CONTRIBUTIONS}

Aurangzeb: Data Analysis and its interpretation, Abstract and Conclusion writing.

Muhammad Asif: Data Collection, working on literature, writing references, and completing research review the article.

Muhammad Kashif Amin: Data Collection, working on literature, writing references, and researching the article after completing the research.

\section{REFERENCES}

1. Adner, R., \& Helfat, C. E. (2003). Corporate effects and dynamic managerial capabilities. Strategic Management Journal, 24(10), 1011-1025. https://doi.org/10.1002/smj.331

2. Almaamari Q. and Abdulrab M. (2017). Factors affecting customer loyalty in service organizations. International Journal of Energy Policy and Management, 2(5), 25-31.

3. Azadeh Dabbaghi, (2017). Identification and Prioritization of the Criteria Measuring Organizational Capital in the Oil Industry using Grey Systems Theory. Petroleum Business Review, 1(1).

4. Becker G. and Gerhart B. (1996). The impact of human resource management on organizational performance: progress and prospects. The Academy of Management Journal, 39(4), 779 -801. https://doi.org/10.2307/256712

5. Bollen, K.A. (1990). overall fit in covariance structure models: Two types of sample size effects. Psychological Bulletin, 107(2), 256-59. https://doi.org/10.1037/0033-2909.107.2.256

6. Clarke T\& Rollo C. (2001). Corporate initiatives in knowledge management. Journal Education Training, 43 (5), 206-214. https://doi.org/10.1108/00400910110399201

7. Diamantopoulos, A. and Siguaw, J.A. (2000), Introducing LISREL. London: Sage Publications. https://doi.org/10.4135/9781849209359

8. Edvinsson, L. and Malone, M. (1997). Intellectual capital: realizing your company's true value by finding its hidden brainpower. Harper Collins, New York.

9. Fernandez E., Montes J.M., Vazquez C.J. (2000). Typology and strategic analysis of intangible resources: a resource-based approach. Tec novation, 20(20), 81-92. https://doi.org/10.1016/S0166-4972(99)00115-7

10. Fiala Roman, Borůvková Jana, (2012). The valuation of organizational capital. Journal of Competitiveness, 4(4), 123-132. https://doi.org/10.7441/joc.2012.04.09

11. Gerbing, D.W. and Anderson, J.C. (1993). On the meaning of within-factor correlated measurement errors. Journal of Consumer Research, 11 (6), 572-80. https://doi.org/10.1086/208993

12. Gunasekaran A, Ngai EWT, McGaughey RE (2006). Information technology and systems justification: a review for research and applications. Eur. J. Oper Res, 173, 957-983. https://doi.org/10.1016/j.ejor.2005.06.002

13. Hu, L.T. and Bentler, P.M. (1999). Cutoff criteria for fit indexes in covariance structure analysis: conventional criteria versus new alternatives structural equation analysis: conventional criteria versus new alternatives. Structural Equation Modeling, 6(1), 1-55. https://doi.org/10.1080/10705519909540118

14. Lawson B, Tyler B. Cousins P. (2008). Antecedents and consequences of social capital on buyer performance. J. Oper, Manage, 26, 446. https://doi.org/10.1016/j.jom.2007.10.001

15. Khan, K. M., Ullah M. (2021). Mediating Role of Ethical Leadership Between Employees Empowerment and Competitive Edge: A Case of Commercial Banks in Pakistan. Humanities \& Social Sciences Reviews, 9(2), 219-231. https://doi.org/10.18510/hssr.2021.9223

16. Lin H.-F., (2007). knowledge sharing and firm innovation capability: an empirical study. International Journal of Manpower, 28, 315-332. https://doi.org/10.1108/01437720710755272

17. MacCallum R. C., Keith F. Widaman, Kristopher J. Preacher and Sehee Hong. (2001). Sample size in factor analysis: the role of model error sample size in factor analysis: the role of model error. Multivariate Behavioral Research, 36 (4), 611-637. https://doi.org/10.1207/S15327906MBR3604_06

18. MacCallum, R.C., Browne, M.W., and Sugawara, H., M. (1996). Power analysis and determination of sample size for covariance structure modeling. Determination of sample size for covariance structure modeling. Psychological Methods, 1(2), 130-49. https://doi.org/10.1037/1082-989X.1.2.130

19. Marsh, H.W., Hau, K.T., and Wen, Z. (2004). In search of golden rules: comment on hypothesis-testing approaches to setting cutoff values for fit indexes and dangers in overgeneralizing hu and Bentler's findings. Structural Equation Modeling, 1(3), 320-41. https://doi.org/10.1207/s15328007sem1103_2

20. Miles, J. and Shevlin, M. (2007). A time and a place for incremental fit indices. Personality and individual differences, 42(5), 869-74. https://doi.org/10.1016/j.paid.2006.09.022 
21. Murphy, M. (2002). Organizational change and firm performance. OECD science, technology and industry Working Papers, 2002/14, OECD Publishing.

22. Nonaka, Toyama \& Konno, (2000). SECI, Ba and leadership: a unified model of dynamic knowledge creation. Long Range Planning, 33(1), 5-34. https://doi.org/10.1016/S0024-6301(99)00115-6

23. Olufunmilola (Lola) Dada and Helen Fogg, (2016). Organizational learning, entrepreneurial orientation, and the role of university engagement in SMEs. International Small Business Journal, 34(1), 86-104. https://doi.org/10.1177/0266242614542852

24. Schermelleh-Engel, K., Moosbrugger, H., and Müller, H. (2003). Evaluating the fit of structural equation models: tests of significance and descriptive goodness-of-fit measures. Methods of Psychological Research Online, 8(2), 23-74.

25. Sharma, S., Mukherjee, S., Kumar, A., and Dillon, W.R. (2005). A simulation study to investigate the use of cutoff values for assessing model fit in covariance structure models. Journal of Business Research, 58 (1), 935 43. https://doi.org/10.1016/j.jbusres.2003.10.007

26. Subramaniam and Youndt A. (2017). The influence of intellectual capital on the type of innovative capabilities. Academy of Management Journal, 48(3), 450-463. https://doi.org/10.5465/amj.2005.17407911

27. Teece, D. J., \& Pisano, G. (1994). the dynamic capabilities of firms: an introduction. Industrial and corporate change, 3(3), 537- 556. https://doi.org/10.1093/icc/3.3.537-a

28. Teece, D. J., G. Pisano and A. Schuen (1997). Dynamic capabilities and strategic management. Strategic Management Journal, 18(7), 509-533. https://doi.org/10.1002/(SICI)1097-0266(199708)18:7<509::AIDSMJ882>3.0.CO;2-Z

29. Vandenberg, R. J. (2006). Statistical and methodological myths and urban legends. Organizational Research Methods, 9(2), 194-201. https://doi.org/10.1177/1094428105285506

30. Wang, C.L. and Ahmed, P.K. (2007). Dynamic capabilities: a review and research agenda. International Journal of Management Reviews, 9, 31-51. https://doi.org/10.1111/j.1468-2370.2007.00201.x

31. Ullah, M., Afghan, N., Afridi, A.S. (2019). Effects of corporate governance on capital structure and financial performance: empirical evidence from listed cement corporations in Pakistan. Global Social Sciences Review, 4(3), 273-283. https://doi.org/10.31703/gssr.2019(IV-III).25

32. Ullah, M., Malik., A.M., Zeb, A., Rehman, A. (2019). Mediating role of capital structure between corporate governance and risk. Journal of Managerial Sciences, 13(3), 47-56.

33. Ullah, M. (2020). Women empowerment and social development in Afghanistan through microfinance. International Journal of Academic Research in business and Social Sciences, 10(12), 377-389. https://doi.org/10.6007/IJARBSS/v10-i12/8324

34. Wheaton, B., Muthen, B., Alwin, D., F., and Summers, G. (1997). Assessing reliability and stability in panel models. Sociological Methodology, 8(1), 84-136. https://doi.org/10.2307/270754 